\title{
Speaking with Policymakers About Current Issues ${ }^{1}$
}

\author{
Alexa J. Lamm²
}

\section{Introduction}

The future of the agricultural and natural resource (ANR) industry requires that educators, industry professionals, and policymakers work together when addressing contentious issues. However, discussing contentious issues with policymakers at the local, state, and national level is not always an easy task. Policymakers in general are busy people with many issues competing for their limited time. Once in the door, it is important to deliver strong messages in the right way for the policymaker to listen and use your information when making important decisions. This publication 1) discusses the differences between education and persuasion and when to use each, 2) offers information on how to make presentations to policymakers in a way that will get their attention, and 3) identifies things to avoid when visiting with a policymaker.

\section{Education versus Persuasion}

Education and persuasion are two different concepts. Education is used to increase knowledge and broaden someone's horizons. It offers complex perspectives that the individual may not have already known and then provides options for associated action. Persuasion is used to narrow down options to the point where a decision maker is motivated to select only one. When discussing current issues with policymakers, you may need to start by educating them about the issue and then use persuasion to focus their attention on a small number of options. The Food and Agricultural Organization of the United Nations (FAO,
2011) has detailed several different kinds of messages you may have to convey to your audience:

- Awareness. (Education) A policymaker must be aware of a problem in order to act upon it.

- Importance. (Education) The scale of the problem, including how large of an impact the problem is having on people, the environment, the economy, etc.

- Analysis. (Education) Background information on what caused the problem and the resulting effects.

- Options. (Education) Policy options detailing how the problem can be solved, including the strengths and weaknesses of each.

- Recommendations. (Persuasion) Informed thoughts on the direction the policymaker should move in, including evidence backing up this selection. Should you do this with an elected official, it would be considered lobbying.

\section{Presenting Information to Policymakers}

The following are some key points to consider when presenting information to policymakers:

1. Respect the limited time of policymakers (Gregrich, 2003) - Be concise and to the point. Choose the information, result, or fact the policymaker needs to know and present that first (Berkson, 2002). Try not to spend any more time than necessary detailing your message. If you want to cover more information than you are allowed time for, provide a one- to two-page summary of your main points.

1. This document is AEC489 (formerly WC152), one of a series of the Agricultural Education and Communication Department, UF/IFAS Extension. Original publication date August 2013. Visit the EDIS website at http://edis.ifas.ufl.edu.

2. Alexa J. Lamm, Assistant Professor, Center for Public Issues Education in Agriculture and Natural Resources and Director, National Public Policy Evaluation Center, Agricultural Education and Communication, Gainesville, FL 32611. 
2. Present a compelling story (Stamatakis, McBride, \& Brownson, 2010) - Storytelling is an extremely effective tool when communicating with policymakers. Turning facts and figures into a real-life scenario that impacts an individual has been used extensively in political communication. Therefore, stories and pictures can often trump statistical data.

3. Remember that policymakers are not specialists in your area - Policymakers come from a variety of backgrounds and may not know much about your topic. As a result they are unlikely to understand jargon, acronyms, and complicated explanations (FAO, 2011). Keep your points simple, while not too elementary.

4. Present timely information (Gregrich, 2003) - Think about the decision cycles and calendars of executive or legislative policymakers. If your message is not immediately pertinent to an issue they are or will be making a decision on, they are less likely to listen as intently.

5. Understand the limits a policymaker works within - Keep in mind that the information you are presenting may conflict with the political or economic realities of the policymaker's current situation (Berkson, 2002). These realities may drive the questions they ask and what they do with your information.

6. Respect the values and insights of policymakers - Policymakers want to hear from individuals that represent all sides of an issue. They come to the table with differing levels of subject-matter knowledge and may not know much about your issue, but they are adept at understanding how information can/will be applied to their constituents.

\section{Things to Avoid when Speaking with Policymakers}

There are certain things that will immediately turn off a policymaker, resulting in their dismissal of you and your message. A few things to avoid when visiting a policymaker include:

- Presenting background information that is already known - Look into the policymaker's background to see what subjects they may/may not be familiar with prior to meeting.

- Poor presentation skills - Practice your speech prior to walking in the room. Think about what you want to say and how you want to say it ahead of time so you avoid mumbling through portions of your presentation.

- Straying from the topic at hand - While stories emphasizing your point are important to bring the issue into context, straying to other topics will be a sure sign you did not come in with a clear message.
- Offering too many details - Policymakers have limited time and staff to read over detailed reports. Hit the highlights and then address the action you hope to see.

- Taking more time than is needed - If you can tell your story in three minutes, try not to take fifteen. Get right to the point and avoid wasting time.

- Using too many complicated graphs and figures - A few significant statistics are great to highlight your main points, but complicated graphs and figures will lose a policymaker's interest quickly.

\section{Conclusion}

Policies impacting the agriculture and natural resource industry are made every day. In order to ensure that all sides of a story are told, it is important for educators and professionals within the industry to communicate their messages and stories to policymakers. In addition, most policymakers are interested in hearing diverse points of view and welcome a variety of information that can inform their decision-making process. In order to do this effectively, strategies outlined in this publication can be used to help your messages be heard.

This publication is part of a series to address the communication, evaluation, and leadership needs of stakeholders in Florida's agricultural and natural resource sectors developed by the UF/IFAS Center for Public Issues Education in Agriculture and Natural Resources and the UF/IFAS National Public Policy Evaluation Center for Agriculture and Natural Resources.

\section{References}

Berkson, J. (2002). An example of integrating within the curriculum: The technical briefing. Wildlife Society Bulletin, 20(1), pp. 242-246. Available at http://www.jstor.org/ stable/3784659

FAO. (2011). Food security communications toolkit. Food and Agriculture Organization of the United Nations: Rome, Italy.

Gregrich, J. R. (2003). A note to researchers: Communicating science to policy makers and practitioners. Journal of Substance Abuse Treatment, 25(3), pp. 233-237. Doi: 10.1016/S0740-5472(03)00120-X

Stamatakis, K. A., McBride, T. D., \& Brownson, R. C. (2010). Communicating prevention messages to policy makers: The role of stories in promoting physical activity. Journal of Physical Activity and Health, 7(1). 